\title{
Programas de luz sobre o desempenho e parâmetros seminais de galos semi-pesados
}

\author{
Lightning programs on the performance and seminal parameters of semi-heavy roosters
}

\author{
Mônica Patrícia Maciel ${ }^{\mathrm{I}}$ Judas Tadeu de Barros Cotta ${ }^{\mathrm{II}}$ Luis David Solis Murgas ${ }^{\mathrm{II}}$ \\ Daniele de Lima ${ }^{\mathrm{III}}$ Fernanda Pinheiro Lima ${ }^{\mathrm{IV}}$ Ana Luisa Neves Alvarenga ${ }^{\mathrm{V}}$
}

RESUMO

Com o objetivo de avaliar a influência de diferentes programas de luz sobre os parâmetros seminais de galos de linhagem semi-pesada, foram utilizados 24 galos da linhagem Lohman Brown com idade inicial de 19 semanas, sendo submetidos a três tratamentos: 1) programa de luz contínuo; 2) programa de luz intermitente e 3) programa de luz natural crescente. Os animais foram distribuídos num delineamento experimental inteiramente casualizado, com oito repetições, sendo a unidade experimental constituída de um animal. $O$ período experimental teve duração de 140 dias e as variáveis avaliadas foram: consumo de ração ( $g$ ave-1 dia-1); peso corporal (g); produção de sêmen ( $\mathrm{ml})$, motilidade (\%) e vigor espermáticos (0 a 5), concentração espermática (número de células $\left.\times 10^{9}\right)$, número de células espermáticas totais $(N C T=$ volume $x$ concentração) e morfologia espermática (alterações de cabeça, cauda e alterações totais). Os galos submetidos aos programas de luz contínuo e intermitente apresentaram maior produção de sêmen e maior $\operatorname{NCT}(P<0,05)$, não havendo influência $(P>0,05)$ dos tratamentos sobre as demais variáveis. Conclui-se que os programas de luz contínuo e intermitente podem ser utilizados para galos semi-pesados durante o período reprodutivo, sem prejudicar o desempenho e os parâmetros seminais.

Palavras-chave: luz contínua, luz intermitente, luz natural, produção, sêmen.

\section{ABSTRACT}

This study aimed to evaluate the influence of different lighting programs on the performance and semen parameters of semi-heavy cock strain. Twenty four roosters, aging 19 weeks, of the Lohman Brown strain were used, and submitted to three treatments: 1) continuous lightning programs 2) intermittent lightning programs and 3) increasing natural lightning programs. The animals were distributed into a completely randomized design, with 8 replicates being the experimental unit constituted of 1 animal. The experimental period lasted 140 days and the evaluated variables were: feed intake (g/chicken/day), body weight $(\mathrm{g})$, semen production $(\mathrm{ml})$, motility (\%) and vigor (0 to 5) of the sperm, spermatic concentration (cells number $\times 10^{9}$ ), total spermatic cells (NCTvolume $x$ concentration) and spermatic morphology (head, tail and total alterations). The semi-heavy roosters submitted to continuous and intermittent lightning programs presented greater semen production and greater NCT $(P<0,05)$. There was no significant influence $(P>0.05)$ of the treatments on the other variables. It was concluded that the programs of continuous and intermittent light can be used for semi-heavy cocks during the breeding season, without sacrificing performance and sêmen parameters.

Key words: continuous light, intermittent light, natural light, production, semen.

\section{INTRODUÇÃO}

A fertilidade de matrizes é um ponto crítico, uma vez que determina o número de pintos produzidos por ave alojada. Nesse contexto, os machos desempenham um importante papel na fertilidade, visto

\footnotetext{
'Departamento de Ciências Agrárias, Universidade Estadual de Montes Claros (UNIMONTES), 39440-000, Janaúba, MG,

Brasil. E-mail: monicapatriciamaciel@yahoo.com.br. Autor para correspondência.

"Departamento de Zootecnia, Universidade Federal de Lavras (UFLA), Lavras, MG, Brasil.

"IIDepartamento de Medicina Veterinária, UFLA, Lavras, MG, Brasil.

${ }^{\mathrm{IV}}$ Centro Universitário de Formiga (UNIFOR), Formiga, MG, Brasil.

${ }^{v}$ Departamento de Zootecnia, Universidade Federal de Minas Gerais (UFMG), Belo Horizonte, MG, Brasil
} 
que a proporção normalmente utilizada nas granjas é de um galo para $10 \mathrm{dez}$ galinhas (COTTA, 2002). Isso sugere que quaisquer alterações na produção ou qualidade do sêmen dos machos podem gerar prejuízos tanto na produtividade da granja quanto na qualidade dos pintos produzidos.

Dos fatores ambientais existentes, um dos que mais afeta a reprodução dos galos é o fotoperíodo, visto que influencia diretamente na produção de hormônios sexuais. Em aves de postura, já é bastante conhecida a função da luz com o objetivo de aumentar o fotoperíodo e estimular a produção de ovos (FREITAS, 2009). Entretanto, pesquisas sobre os efeitos da luz sobre as funções reprodutivas do macho são limitadas (MACIEL et al., 2009).

Um aspecto interessante da fisiologia das aves é que elas não necessitam estar submetidas a dias longos continuamente, ou seja, não há a necessidade do fornecimento de luz diária constantemente. Esse fenômeno é denominado "dia subjetivo", no qual aves adultas em produção ignoram períodos de escuridão incluídos entre as 14 e 16 horas estimulantes. $\mathrm{O}$ dia subjetivo designa o período no qual a ave permanece fisiologicamente ativa mesmo na obscuridade. Nesse período, os animais ignoram a fase escura, porém sem reduzir a produção e secreção de hormônios relacionados à reprodução. Esse fenômeno permite o uso de programas ou fotoperíodos chamados "intermitentes" os quais podem ser definidos como aqueles formados por mais de um período de luz e obscuridade em um ciclo de 24 horas (COTTA, 2002).

SIOPES (1983) estudou a influência de luz intermitente sobre a economia de energia elétrica e as características seminais de perus adultos. Foi observado que, embora os perus tivessem mantido pesos corporais semelhantes, os animais que receberam luz intermitente consumiram menos ração e produziram quantidades equivalentes de sêmen com número de espermatozóides semelhantes durante todo o período experimental em comparação ao controle (luz contínua). Foi observada menor incidência de espermatozóides morfologicamente anormais nos animais submetidos à luz intermitente, havendo ainda uma economia de $73 \%$ de energia elétrica com a utilização dos programas intermitentes. Também em pesquisa com perus, resultados semelhantes foram observados por BACON et al. (1994), os quais não verificaram diferenças entre os programas intermitentes e contínuos em relação ao peso corporal, peso testicular e produção de sêmen.

Em pesquisa com galos de linhagem leve, MACIEL et al. (2009) testaram um programa de iluminação intermitente (consistindo em 2 flashes de luz de madrugada) e outro com apenas luz natural crescente em comparação com um programa contínuo de 15 horas. Os autores não observaram diferenças nos resultados de produção e qualidade de sêmen entre as aves que foram submetidas aos diferentes programas, concluindo que tanto o programa intermitente, quanto o programa com apenas luz natural crescente podem ser adotados como uma alternativa ao comumente utilizado (contínuo de 15 horas).

O presente trabalho teve como objetivo avaliar a influência de diferentes programas de luz sobre o desempenho e parâmetros seminais em galos de linhagem semi-pesada.

\section{MATERIAL E MÉTODOS}

O período experimental teve a duração de 20 semanas, sendo utilizado um galpão dividido em três compartimentos por lona de plástico preta, de forma a evitar a passagem de luz de um ambiente para outro. Foram utilizados 24 galos da linhagem Lohmann Brown com idade inicial de 19 semanas (oito por tratamento), sendo alojados individualmente em cada gaiola. A ração fornecida durante o período experimental, à base de milho e farelo de soja, continha $14,8 \%$ de proteína bruta, $2900 \mathrm{kcal}$ de energia metabolizável, $1 \%$ de cálcio e $0,37 \%$ de fósforo disponível. Foram fornecidas $110 \mathrm{~g}$ de ração ave $^{-1}$ dia $^{-1}$ na frequência de duas vezes ao dia. Em dois dos ambientes experimentais, foram instalados timers com o objetivo de acender e apagar as luzes nos horários determinados. No ambiente com iluminação intermitente, acoplado ao timer, foi instalado um temporizador que possibilitou desligar as luzes 15 segundos após serem acesas. As lâmpadas utilizadas foram do tipo incandescente de 60 Watts, sendo fornecida uma intensidade mínima de luz de 12,6 Lux.

A partir da idade de 19 semanas, foi feita a estimulação diária dos galos para as coletas de sêmen para que fossem condicionados ao procedimento na fase experimental. A estimulação foi realizada pelo método de massagem abdominal, conforme BURROWS \& QUINN (1937). Os tratamentos utilizados foram: 1) programa de luz contínuo: as lâmpadas foram acesas às 4 horas e desligadas na aurora, acesas novamente ao anoitecer e apagadas às 19 horas, de forma a receberem um fotoperíodo contínuo de 15 horas; 2) programa de luz intermitente: as lâmpadas foram acesas às 4 horas e apagadas 15 segundos após. Eram novamente acesas às 18 horas, 59 minutos e 45 segundos e apagadas às 19 horas. Evocando-se o conceito de dia subjetivo, foi fornecido, então, um fotoperíodo intermitente de 15 horas; 3) programa de luz natural: somente foi fornecida iluminação natural crescente. 
As avaliações das características seminais foram feitas nas idades de 24, 29, 34 e 39 semanas dos animais, sendo: produção (volume) de sêmen, concentração espermática, número total de células espermáticas, motilidade, vigor e morfologia espermática. Para a avaliação da motilidade, retirou-se uma gota de sêmen de cada galo imediatamente após a coleta, colocando-a sobre lâmina recoberta por lamínula previamente aquecida à temperatura de $40^{\circ} \mathrm{C}$ para a leitura no microscópio ótico (100X). O volume de sêmen de cada galo foi medido diretamente na seringa de $0,1 \mathrm{~mL}$. Para análise da concentração espermática, foi retirada uma amostra de $10 \mu \mathrm{l}$ de sêmen de cada galo para ser adicionado a $1 \mathrm{~mL}$ de solução de formol citrato, sendo a contagem realizada com o uso da câmara de Neubauer com o resultado expresso em número de células por ml de sêmen. $\mathrm{O}$ NCT (número de células totais) foi calculado pela multiplicação da concentração e volume do ejaculado de cada galo. Para avaliação das anormalidades dos espermatozóides, $1 \mu \mathrm{l}$ de sêmen de cada galo foi adicionado a $250 \mu 1$ de solução de formol citrato $(2,9 \mathrm{~g}$ de citrato de sódio, $4 \mathrm{~mL}$ de formaldeído a $4 \%$ e água destilada q.s.p.). Seguidamente, no microscópio de contraste de fase da marca Nikon com aumento de 1000x, realizou-se a contagem de 100 células, expressando as alterações morfológicas em percentagem (alterações de cabeça, cauda e alterações totais). As diferenças entre tratamentos foram comparadas pelo teste Scott-Knott (5\%) e para análise dos dados foi utilizado o programa computacional SISVAR (Sistemas para análises de variância para dados balanceados), segundo FERREIRA(2000).

\section{RESULTADOS E DISCUSSÃO}

Na tabela 1, são apresentados os resultados de produção, concentração, número de células totais, motilidade e vigor do sêmen de galos semi-pesados de acordo com o programa de luz. Os programas de luz não influenciaram no consumo de ração $(\mathrm{P}>0,05)$. Em pesquisa com poedeiras semi-pesadas, FREITAS et al. (2003) observaram resultado semelhante, já que as aves que receberam iluminação intermitente, natural ou contínua apresentaram consumo semelhante. No entanto, SIOPES (1983), estudando a influência de luz intermitente sobre o desempenho e características seminais de perus adultos, observou que os animais que receberam luz intermitente consumiram menos ração que aqueles submetidos ao programa de luz contínuo. Segundo o autor, a explicação para o ocorrido pode ser devido à redução da atividade dos animais do programa intermitente, gerando uma menor exigência de energia de mantença, levando a um menor consumo de ração. Essa explicação é concordante com ETCHES (1996) que afirma que o efeito do fotoperíodo sobre o consumo de ração depende da atividade locomotora da ave, que fica reduzida ao mínimo nos períodos escuros. Com a diminuição dos movimentos, o gasto de energia é também reduzido, fazendo melhorar a eficiência alimentar nos fotoperíodos intermitentes.

Com relação ao peso corporal, que também não sofreu influência $(\mathrm{P}>0,05)$ dos programas de luz, a semelhança observada entre as médias indica que a utilização de programa intermitente, bem como a ausência de luz artificial em períodos de luminosidade crescente (luz natural), não afeta o peso corporal das aves. SIOPES (1983) e BACON et al. (1994) também não observaram diferenças entre os pesos corporais de perus adultos submetidos aos programas contínuo e intermitente, apesar de os animais submetidos a este último terem consumido menor quantidade de ração. No entanto, LEWIS \& PERRY (1989) e LEWIS et al. (1992) verificaram menores pesos corporais de poedeiras mantidas sob luz intermitente quando comparadas àquelas sob luz contínua. Em ambos os trabalhos, os menores pesos foram consequência da diminuição do consumo de ração das aves do programa intermitente.

O volume de sêmen foi semelhante $(\mathrm{P}>0,05)$ nos programas de luz contínuo e intermitente, resultado esse que concorda com aqueles obtidos por SIOPES

Tabela 1 - Consumo de ração (CR), peso corporal (PC), produção de sêmen (PS), concentração do sêmen (CS), número de células totais do sêmen (NCT), motilidade (MOT) e vigor (VIG) dos espermatozóides de galos semi-pesados de acordo com o programa de luz*.

\begin{tabular}{lclccccc}
\hline Programa de Luz & $\begin{array}{c}\mathrm{CR} \\
\left(\mathrm{g} \mathrm{ave}^{-1} \mathrm{dia}^{-1}\right)\end{array}$ & PC $(\mathrm{g})$ & PS $(\mathrm{ml})$ & CS $\left(\times 10^{9}\right)$ & NCT $\left(\times 10^{9}\right)$ & MOT (\%) & VIG (0 a 5) \\
\hline Contínuo & 111,30 & 2833,60 & $0,22 \mathrm{~A}$ & 5,67 & $1,29 \mathrm{~A}$ & 78,28 & 3,28 \\
Intermitente & 110,90 & 2843,7 & $0,21 \mathrm{~A}$ & 5,81 & $1,28 \mathrm{~A}$ & 73,44 & 3,00 \\
Natural & 110,60 & 2824,20 & $0,17 \mathrm{~B}$ & 4,32 & $0,75 \mathrm{~B}$ & 75,16 & 3,22 \\
CV $(\%)$ & 5,90 & 7,66 & 44,62 & 32,68 & 42,38 & 18,81 & 19,75 \\
\hline
\end{tabular}

"Médias seguidas de letras maiúsculas na coluna diferem pelo teste Scott-Knott $(\mathrm{P}<0,05)$. 
(1983) e BACON et al. (1994) que também não observaram diferenças entre o volume de sêmen de perus adultos submetidos à luz intermitente e contínua. Em pesquisas com poedeiras, alguns autores observaram que o fracionamento da duração do dia com a manutenção de uma noite principal (iluminação intermitente) permite manter a produtividade (MIDGLEY et al., 1988; LEWIS \& PERRY, 1990; SAUVEUR,1996).

Os galos do experimento com programa de luz natural apresentaram volume de sêmen menor $(\mathrm{P}<0,05)$, quando comparados àqueles do experimento com luz intermitente e contínua. Já MACIEL et al. (2009), em pesquisa com galos leves, observaram que tanto o programa intermitente quanto o programa com apenas luz natural crescente, proporcionaram resultados semelhantes ao comumente utilizado (contínuo de 15 horas), mostrando que esse tipo de linhagem se adapta melhor a períodos com menor fornecimento de luz. $\mathrm{O}$ resultado encontrado por esses autores vai de encontro com os trabalhos revisados por CHARLES \& TUCKER (1993), que observaram que híbridos de postura modernos são tão geneticamente predispostos à alta produção que praticamente se apresentam refratários a mudanças de regime luminoso. Porém, os trabalhos revisados se referem apenas a linhagens leves. FREITAS (2003), que observou menor produção de ovos em poedeiras semi-pesadas mantidas sob programa de luz natural, concluiu que a afirmativa feita pelos autores citados talvez não possa ser aplicada às aves semi-pesadas, pois a evolução genética delas ainda é inferior à das leves.

Com relação à concentração espermática, não foi observada influência $(P>0,05)$ dos programas de luz sobre essa característica. Esse resultado concorda, em parte, com aqueles encontrados por SIOPES (1983), que não observaram diferenças nesta variável, em perus mantidos sob luz intermitente e contínua.

O número de células totais (NCT) é obtido pela multiplicação do volume e concentração espermáticos. Os resultados referentes a esse parâmetro foram semelhantes nas aves mantidas em programas contínuos e intermitentes e maiores que aquelas sob luz natural. Esse resultado se deve ao maior volume de sêmen produzido, já que a concentração não variou entre os animais mantidos nos diferentes programas.

Segundo ETCHES (1994), no momento da ejaculação, as células espermáticas são misturadas a líquidos (fluido linfático) secretados a partir do aparelho fálico ingurgitado. Pode-se inferir que os animais criados sob programas contínuo e intermitente produziram maiores quantidades deste líquido, o que acabou refletindo nos maiores resultados do NCT.

Não houve influência $(\mathrm{P}>0,05)$ dos programas de luz sobre a motilidade (\%) e o vigor espermático ( 0 a 5 ). Resultado semelhante foi observado por Maciel et al. (2009) em pesquisa com galos leves em que os animais apresentaram motilidade e vigor espermáticos semelhantes. Segundo GOMES (1970), a motilidade é um dos testes utilizados para avaliar a qualidade do sêmen, podendo ser considerado um bom indicador da viabilidade espermática geral e de sua capacidade fertilizante. Como não foi observada diferença entre os programas de luz, pode-se afirmar que, sob luz contínua e intermitente, bem como somente luz natural, em dias de luminosidade crescente, a qualidade nãoé afetada. GARNER (2004) afirma que a variação média normal na taxa de motilidade espermática em galos se encontra entre 60 e $80 \%$. Nesse experimento, nenhum dos programas utilizados afetou negativamente a motilidade, pois a média observada foi de $75,7 \%$, estando, portanto, dentro dos padrões normais.

Os dados de morfologia espermática, incluindo alterações de cabeça e de cauda e alterações totais, estão apresentados na tabela 2 . Não houve influência dos programas de luz $(\mathrm{P}>0,05)$ sobre as alterações. Trabalhos abordando a morfologia espermática em galos são bastante raros e em menor número são aqueles que relacionam esses achados aos problemas reprodutivos de um plantel. Qualquer alteração com relação às características morfológicas normais pode comprometer a motilidade e a sobrevivência do espermatozóide, sendo uma forma de desclassificação do macho para a reprodução (JAENISCH, 1998). A percentagem de alterações espermáticas foi semelhante $(\mathrm{P}>0,05)$ nos programas de luz testados. Diferentemente desse resultado, SIOPES (1983) verificou uma menor taxa de espermatozóides morfologicamente anormais em perus submetidos à luz intermitente, em comparação com aqueles submetidos à luz contínua. No entanto, MACIEL et al. (2009) não observou diferença na

Tabela 2 - Alterações de cabeça (ACAB), alterações de cauda (ACAU) e alterações totais (ATOT) dos espermatozóides de galos semi-pesados de acordo com o programa de luz.

\begin{tabular}{lccc}
\hline Programa de Luz & ACAB $(\%)$ & ACAU $(\%)$ & ATOT $(\%)$ \\
\hline Contínuo & 2,88 & 6,38 & 9,50 \\
Intermitente & 2,32 & 6,16 & 8,78 \\
Natural & 5,22 & 6,35 & 12,07 \\
CV $(\%)$ & 67,65 & 42,51 & 60,80 \\
\hline
\end{tabular}


morfologia dos espermatozóides de galos leves quando comparou o programa intermitente com os demais (contínuo e natural crescente).

Nenhum dos programas de luz prejudicou a morfologia espermática. SURAI \& WISHART (1996) afirmam que um limite de até $20 \%$ de defeitos espermáticos totais é aceitável para uma boa fertilidade. No presente trabalho todos os programas proporcionaram valores abaixo de $20 \%$, demonstrando que eles podem ser utilizados sem afetar a qualidade morfológica do sêmen de galos semi-pesados.

\section{CONCLUSÃO}

Galos de linhagem semi-pesada podem ser mantidos sob programas de luz contínuo e intermitente sem prejudicar os parâmetros de desempenho e os reprodutivos. Porém, o programa de luz natural crescente não é recomendado para esse tipo de linhagem, pois proporciona diminuição do volume e do número de células totais do sêmen.

\section{REFERÊNCIAS}

BACON, W.L. et al. Coordinate pattern of secretion of luteinizing hormone and testosterone in mature male turkeys under continuous and intermittent photoschedules. Poultry Science, Champaign, v.73, p.864-870, 1994.

BURROWS, W.H.; QUINN, J.P. The collection of spermatozoa from the domestic fowl and turkey. Poultry Science, Champaign, v.16, p.19-24, 1937.

CHARLES, D.R.; TUCKER, S.A. Response of modern hybrid laying strocks to change in photoperiod. British Poultry Science, London, v.34, p.241-254, 1993.

COTTA, J.T.B. Galinha: produção de ovos. Viçosa: Aprenda Fácil, 2002. 270p.

ETCHES, R.J. Inseminação artificial. In: Fisiologia da reprodução de aves. Santos: Apinco, 1994. p.117-128.

ETCHES, R.J. Reproducción aviar. Zaragoza: Acribia, 1996. $339 \mathrm{p}$.

FERREIRA, D.F. SISVAR Sistema de análise estatística para dados balanceados. Lavras: UFLA/DEX, 2000. Software.

FREITAS, H.J. Avaliação de programas de iluminação para poedeiras leves e semi-pesadas. 2003. 99f. Tese
(Doutorado em Zootecnia) - Curso de Pós-graduação em Zootecnia, Universidade Federal de Lavras, MG.

FREITAS, H.J. et al. Avaliação de programas de iluminação sobre o desempenho zootécnico de poedeiras leves. Ciência e Agrotecnologia, Lavras, v.29, n.2, p.424-428, 2005. Disponível em: <http://www.scielo.br/pdf/cagro/v29n2/a21.pdf>. Acesso em: 20 dez. 2009. doi: 10.1590/S141370542005000200021 .

GARNER, D.L. Espermatozóide e plasma seminal. In: HAFEZ, E.S.E.; HAFEZ, B. Reprodução Animal. São Paulo: Manole, 2004. p.97-110.

GOMES, W.R. Artificial Insemination. In: The testes. New York: Academic, 1970. p.257-279.

JAENISCH, F.R.F. Morfologia espermática em galos com diferentes pesos corporais. In: REUNIÃO ANUAL DA SOCIEDADE BRASILEIRA DE ZOOTECNIA, 1998, Fortaleza, CE. Anais... Fortaleza: SBZ, 1998. p.401-403.

LEWIS, P.D.; PERRY, G.C. Effect of asymmetrical lighting on the body weight and carcase composition of laying hens and their influence on the efficiency of food utilization. British Poultry Science, London, v.30, p.223-228, 1989.

LEWIS, P.D.; PERRY, G.C. Response of laying hens to assimetrical interrupted lighting regimens: physiological aspects. British Poultry Science, London, v.31, p.45-52, 1990.

LEWIS, P.D.; PERRY, G.C. et al. Intermittent lighting regimes and mortality rates in laying hens. World's Poultry Science Journal, Ithaca, v.48, p.113-120, 1992.

MACIEL, M.P. et al. Desempenho e características do sêmen de galos leves submetidos a diferentes fotoperíodos. Ciência e Agrotecnologia, Lavras, v.32, n.4, p.1287-1291, 2008. Disponível em: <http://www.editora.ufla.br/revista/32_4/ (38)\%20Artigo\%203705.pdf >. Acesso em: 10 dez. 2009. doi: 10.1590/S $1413-70542008000400038$.

MIDGLEY, M. et al. Experiment with the biomttent light system for laying hens. British Poultry Science, London, v.21, p.389-394, 1988 .

SAUVEUR, B. Photopériodisme et reproduction des oiseaux domestiques femelles. INRA Production Animal, Paris, v.9, n.1, p.25-34, 1996.

SIOPES, T.D. Effect of intermittent lighting on energy savings and semen characteristics of breeder tom turkeys. Poultry Science, Champaign, v.62, p. 2265-2270, 1983.

SURAI, P.F.; WISHART, G.J. Poultry artificial insemination technology in the countries of the former USSR. World's Poultry Science Journal, Ithaca, v.52, p.27-43, 1996. 